\title{
Nutrition Knowledge, Practices, Attitudes, and Information Sources of Mid-American Conference College Softball Players
}

\author{
Grete R. Hornstrom ${ }^{1}$, Carol A. Friesen ${ }^{2}$, Jane E. Ellery ${ }^{3}$, Kimberli Pike ${ }^{2}$ \\ ${ }^{1}$ Pediatric Nutrition Department, Miller Children's Hospital, Long Beach, USA; ${ }^{2}$ Department of Family and Consumer Sciences, Ball \\ State University, Muncie, USA; ${ }^{3}$ Institute for Wellness and Gerontology, Ball State University, Muncie, USA. \\ Email: cfriesen@bsu.edu
}

Received October 21 $1^{\text {st }}$, 2010; revised February 2 ${ }^{\text {nd }}$, 2011; accepted February $18^{\text {th }}, 2011$.

\begin{abstract}
The number of women participating in softball at the collegiate level continues to rise, yet little is known about collegiate softball players' knowledge about sport nutrition. The purpose of this study was to collect information from Mid-American Conference softball players to determine their current knowledge, attitudes, and practices related to sport nutrition and to identify their preferred sources for obtaining sport nutrition information.
\end{abstract}

Keywords: Sports Nutrition, Nutrition Knowledge, Nutrition Attitudes, Nutrition Practices, College Athlete Nutrition, Preferred Nutrition Sources

\section{Introduction}

Nutrition forms the foundation for physical performance; it provides the fuel for biological work and the chemicals for extracting and using food's potential energy [1]. Research supports that proper nutrient intake corresponds to peak physical performance and that nutrient deficiencies may lead to diminished athletic performance [2,3]. In the past, only elite athletes were concerned with the role of nutrition in athletic performance [4]. Today, most athletes understand that proper fueling through optimal nutrition is an important and integral part of a training program [3,5]. Nonetheless, most collegiate athletes remain poorly educated about sound nutritional practices and are unskilled in making appropriate daily nutritional choices $[6,7]$.

College athletes often turn to athletic trainers, strength and conditioning staff, coaches, or other athletes for nutrition advice, many of whom offer limited factual information concerning sports nutrition [8]. Only a handful of college athletic associations have documented using the expertise of dietetics professionals to enhance their team's performance [5]. Athletes often obtain their nutrition information from the internet or the popular press, especially "muscle" magazines that are quick to hype supplementation and unproven diet manipulations as the way to achieve the ideal image [5]. Magazines and fri- ends were the two most common sources of nutrition information for softball players in one research study [6].

The passing of Title IX in 1972 has had a tremendous impact on women's sports [9]. Softball has become one of the primary sports for women at the collegiate level. In 2008, the five most frequently offered collegiate sports for women in the United States were basketball (98.8 percent of schools have a team); volleyball (95.7\%); soccer (92\%); cross country (90.8\%); and softball (89.2\%) [10]. According to the National Collegiate Athletic Association (NCAA), softball ranks third in the number of new Division I sponsored women's teams between 1988-89 and 2006-07 ( $\mathrm{n}=68$ new teams) behind soccer $(\mathrm{n}=205$ new teams) and golf $(\mathrm{n}=114$ new teams) [11]. Despite the passage of time, little research has been conducted to understand the impact of nutrition and nu-109 trition knowledge on softball performance or food selection behaviors of collegiate softball players.

The purposes of this study were to: 1) measure the nutrition knowledge of Mid-American Conference (MAC) softball players; 2) identify if there was an association between a player's nutrition knowledge and their nutrition choices, nutrition practices, and their attitude toward a sports-enhancing diet; 3) assess the relationship between a softball player's attitude toward a sports-enhancing diet and their typical nutrition choices and nutrition 
practices; 4) identify the preferred sources for obtaining sport nutrition information by these collegiate softball players; and 5) identify if there was a relationship between the players' source of nutrition information and their nutrition knowledge.

\section{Subjects and Methods}

\subsection{Subjects}

The Mid-American Conference (MAC) sanctioned thirteen fastpitch softball teams in the 2003-2004 academic year (e.g., University of Akron, Ball State University, Bowling Green State University, University at Buffalo, Central Michigan University, Eastern Michigan University, Kent State University, Marshall University, Miami University, Northern Illinois University, Ohio University, University of Toledo, and Western Michigan University). The average number of players per team roster was 18 . Subjects in this study were players from the thirteen MAC softball teams. All participants were female. The research protocol and all survey instruments used in the study were approved by Ball State University's Institutional Review Board.

\subsection{Questionnaire}

The survey tool used in this study was developed from a combination of previously administered questionnaires [10,12-17]. The questionnaire items were structured to measure basic nutrition and sports nutrition knowledge (n = 20); nutrition quality of typical food choices $(n=7)$; current dietary practices based on the food guide pyramid $(n=5)$; likely source of information; attitudes toward nutrition $(\mathrm{n}=20)$; and the intention to use proper nutrition to enhance softball performance $(n=6)$.

The questionnaire was pilot tested using the Ball State University tennis team to ensure question items were understood by a similar population. The results of the pilot test suggested changes should be made to the Likert scale used in the questionnaire to force participants to make a decision based on their given knowledge. The revised questionnaire was reviewed by a panel of experts to ensure the questions were relevant to the research topic.

Demographic information collected included the ball players year in school, major, and if they had ever taken a nutrition class. A cover letter explained the purpose of the study and described how to complete the questionnaire. To ensure absolute anonymity of both individual players and teams, the questionnaires were not coded in any way that would allow them to be traced to any team or to any individual.

\subsection{Score Development}

Four scores were computed based on the results of the
Sports Nutrition Questionnaire: 1) Nutrition Knowledge Score (NKS), 2) Nutrition Choice Score (NCS), 3) Nutrition Practice Score (NPS), and 4) Attitude Toward a Sports-Enhancing Diet (ASED) score.

Subjects were asked a series of 80 nutrition questions that ranged in topic from general nutrition to specific effects of nutrients (Table 1). Each question was coded as "correct" or "incorrect," with a correct score getting a value of " 1 " and an incorrect score being assigned a value of " 0 ." The scores for all 80 questions on the Sports Nutrition Questionnaire were summed to create the Nutrition Knowledge Score (NKS).

Seven questions (Table 2) concerning a players' typical nutrition choices were used to create the Nutrition Choice Score (NCS). The possible score on the NCS ranged from a low of seven to a high of 28 , with a low score associated with the healthiest nutrition choices.

Subjects were asked a series of five questions (Table 2) that concerned their typical nutrition practices (Nutrition Practice Score; NPS). Questions were recoded based on current USDA food guide pyramid recommendations (e.g., if a person ate the recommended 2-3 servings of dairy products, that score was recoded with the highest possible value). The possible score on nutrition practice questions ranged from a low of zero to a high of five, with a high NPS score being associated with the healthiest nutrition practices.

A series of 20 questions were asked concerning the subjects' attitudes, subjective norms, perceived behavioral control, and intentions concerning a sport-enhancing diet [Sport-Enhancing Diet: any nutritional changes an athlete may make to their usual diet to enhance athletic performance]. Six of these 20 questions related specifically to the subjects' attitude toward a sport-enhancing diet (ASED) (Table 2). Cronbach's Alpha score for these six questions was 0.79. The subjects' answer to these six attitudinal questions were summed and divided by six to create a mean Attitude toward a Sport-Enhancing Diet (ASED) score. A low ASED score is associated with a more positive attitude toward a sport-enhancing diet.

\subsection{Statistical Analysis}

Data analysis was performed using the SPSS 12.0 software [18]. The relationship between the dependent variables (e.g., nutrition knowledge, nutrition choices, nutrition practices, and athlete's attitude toward a sports enhancing diet) and the outcome variables were examined using frequencies, t-test, crosstabs with adjusted standardized residuals, and Cronbach's alpha. Correlation coefficients were used to compare the relationship between subjects' nutrition knowledge (NKS) with their 
Table 1. Example questions used to create the nutrition knowledge score (NKS).

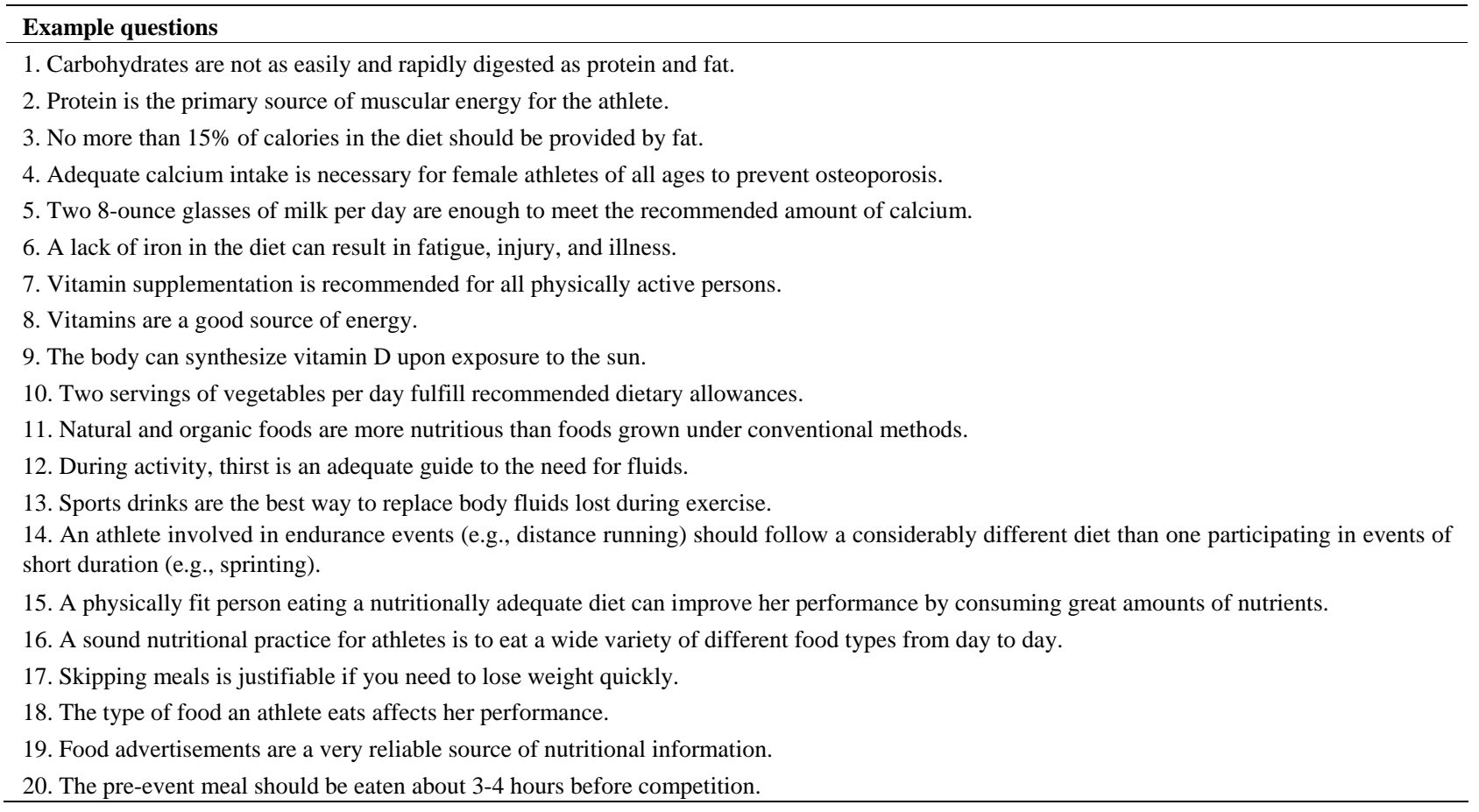

Table 2. Questions used to develop Nutrition Choice Score (NCS), Nutrition Practice Score (NPS), and Attitude toward a Sport-Enhancing Diet (ASED) Score.

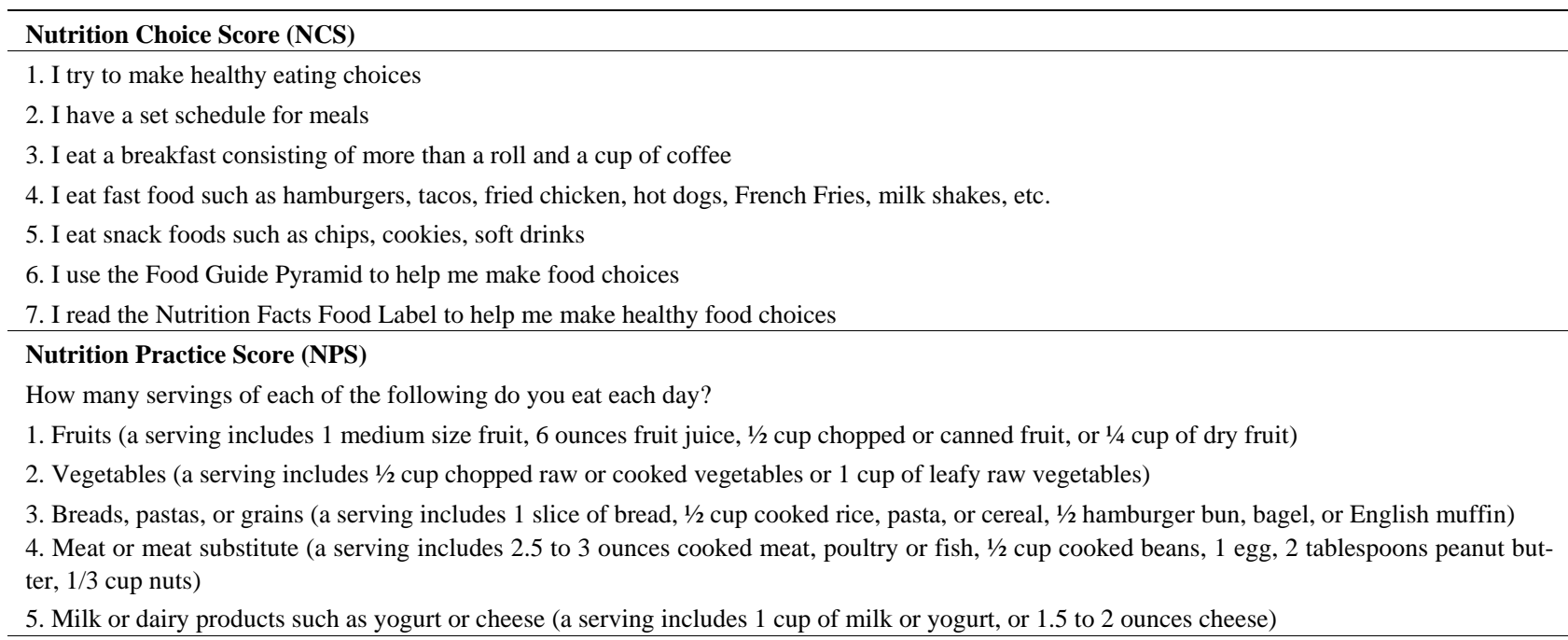

\section{Attitude toward a Sport-Enhancing Diet (ASED) score}

1. For me eating a sport enhancing diet would be harmful

2. Eating a sport enhancing diet will help me to be a more successful softball player

3. For me eating a sport enhancing diet would be enjoyable

4. For me eating a sport enhancing diet would be worthless

5. For me eating a sport enhancing diet would be beneficial

6. For me eating a sport enhancing diet would be valuable

attitude toward a sports-enhancing diet (ASED), their nutrition choices (NCS), and their nutrition practices
(NPS). The level of statistical significance for all tests was $\mathrm{p}<0.05$. 
tween the players' nutrition knowledge score (NKS) and their Attitude toward a Sport-Enhancing Diet (ASED) score $(r=-0.17 ; p=0.02)$, with the higher a subject's NKS, the more positive (e.g., lower score) was their attitude toward a sport-enhancing diet (e.g., eating a sport-enhancing diet will help me to be a more successful softball player).

A significant positive relationship existed between the players' Attitude toward a Sport-Enhancing Diet score (ASED) and their Nutrition Choice Score (NCS) $(r=$ 0.26 ; $\mathrm{p}=0.001$ ) (Table 5). Players who had a more positive attitude (e.g., a lower ASED score) tended to have healthier eating habits (e.g., I try to make healthy eating choices; I have a set meal schedule). No relationship was found between the ASED and the NPS $(r=-0.10 ; p=$ 0.20 ), indicating the subjects' attitude toward a sport-enhancing diet score was not related to their self-reported nutrition practices (e.g., daily intake of USDA Food Guide Pyramid recommended servings). A significant relationship was found, however, between the NCS and the NPS ( $r=-0.38 ; \mathrm{p}=0.000)$, indicating the poorer the subjects' nutrition choices (e.g., a higher NCS), the less likely they were to have consumed the recommended number of daily servings of each food group according to the USDA Food Guide Pyramid (e.g., a lower NPS).

Subjects were asked to indicate their likelihood of using a variety of resources from which current nutrition information could be obtained. A four point scale ranging from "very likely" to "very unlikely" was used. Results indicated the MAC softball players were most likely to use a physician $(1.6 \pm 0.7)$, followed by an athletic

Table 5. Correlations of Nutrition Knowledge Score (NKS), Nutrition Choice Score (NCS), Nutrition Practice Score (NPS), and attitude toward a Sport-Enhancing Diet score (ASED) of MAC softball players $(n=185)$.

\begin{tabular}{|c|c|c|}
\hline Component & $\mathbf{r}$ & $\mathbf{p}$ \\
\hline \multicolumn{3}{|l|}{ Nutrition Knowledge Score (NKS) } \\
\hline Nutrition Choice Score & -0.23 & 0.002 \\
\hline Nutrition Practice Score & 0.23 & 0.002 \\
\hline $\begin{array}{l}\text { Attitude Toward a Sport- } \\
\text { Enhancing Diet Score }\end{array}$ & -0.17 & 0.02 \\
\hline \multicolumn{3}{|l|}{ Nutrition Choice Score (NCS) } \\
\hline Nutrition Practice Score & -0.38 & 0.000 \\
\hline $\begin{array}{l}\text { Attitude Toward a Sport- } \\
\text { Enhancing Diet Score }\end{array}$ & 0.26 & 0.001 \\
\hline \multicolumn{3}{|l|}{ Nutrition Practices Score (NPS) } \\
\hline $\begin{array}{l}\text { Attitude Toward a Sport- } \\
\text { Enhancing Diet Score }\end{array}$ & -0.10 & 0.20 \\
\hline
\end{tabular}

trainer (1.8 \pm 0.8$)$, as their preferred source of nutrition information. College nutrition/health courses $(1.9 \pm 0.8)$ and a dietitian $(1.9 \pm 1.0)$ ranked third and fourth out of the ten options. Interestingly, the least likely sources of nutrition information were the players' coaches (2.5 \pm $0.9)$ and academic journals $(2.9 \pm 0.9)$.

A series of $2 \times 2$ crosstabs were run to examine the relationship between the players nutrition knowledge score (NKS) and their preferred sources of nutrition information (e.g., do people with a high NKS score use more valid sources). A "pass/fail” NKS score (e.g., a score of $60 \%$ or higher on the nutrition knowledge questionnaire resulted in a 'pass' score) and a 'Likely/Unlikely' score for the subject's response to their preferred nutrition information sources (e.g., if they were 'very likely' or 'likely' to use a source, their response was recoded as 'likely') were calculated. Overall, 156 of the 185 respondents indicated they were likely to use an athletic trainer as a preferred source of nutrition information. Of these, $71 \%(n=110 / 156)$ failed the nutrition knowledge questionnaire compared to only $30 \%(n=46 / 156)$ who received a passing score $\left(\chi^{2}=11.4 ; \mathrm{p}=0.001\right)$. In contrasts, two-thirds $(\mathrm{n}=18$; $63 \%)$ of those who passed the nutrition knowledge questionnaire were less likely to use an athletic trainer as a source of nutrition information.

\section{Discussion}

The nutrition knowledge scores (NKS) of the MAC softball players ranged from a low of 29 (36\% correct) to a high of 56 (70\% correct). The mean nutrition knowledge score $(45.7 \pm 4.7)$ was equivalent to answering only 57 percent of the questions correct on the 80 question survey. When the standard 60 percent cut point to define 'failure' was used, two-thirds ( $\mathrm{n}=120 ; 65 \%)$ of the softball players in this study failed the test.

Abood, Black \& Birnbaum reported athletes scored at or slightly below 70 percent on a 42 question nutrition knowledge test, higher than the present study [19]. Douglas and Douglas reported a mean nutrition knowledge score for athletes of 55 percent or 26.4 questions answered correctly out of 48 , similar to the present study [20]. Softball players scored $25.3 \pm 6.5$ or 53 percent, slightly lower than the results of the present study [20]. Other research tended to show even lower nutrition knowledge scores among athletes. Barr found that the average nutrition score for an athlete was about 34 percent [21]. Batson, Sease, Stanek, \& Leski reported 99 percent of athletes surveyed had poor nutrition knowledge [22]. A nutrition knowledge survey completed by college freshman football players at a division I school found that the mean score of the players was $5.5 \pm 1.7$ out of 11 (50\%); none of the athletes scored a perfect 11 
[23]. These findings concur with the present study where athletes' nutrition knowledge continually average below the $60^{\text {th }}$ percentile.

Division I college athletes lead very busy lives and, as a consequence, their dietary choices may be at risk [5]. The MAC softball players' mean Nutrition Choice Score of $19.4 \pm 3.8$ out of 28 in the present study (a higher NCS score indicates poorer nutritional choices) supports this generalization. Over half (54\%) of the MAC softball players indicated they "occasionally" eat at fast food restaurants; $17 \%$ said they eat fast food every day or most days. These results concur with those of Jonnalagadda, et al. who reported freshman college football players ate out at least $4.8 \pm 4.1$ time per week, with the most common place being fast food restaurants [23]. These same football players indicated they ate, on average, $3.6 \pm 1.0$ times per day [23]. Over half of the MAC softball players in the present study $(\mathrm{n}=105 ; 57 \%)$ indicated they 'occasionally,' 'rarely,' or 'never' have a set meal schedule.

Nutrition practices of athletes vary greatly. The USDA MyPyramid is a tool to help consumers, including athletes, make healthier choices. Research indicates individuals who eat the "Food Guide Pyramid way" have healthier diets [24]. In the present study, the MAC softball players' diets met only $2.8 \pm 1.3$ out of the five USDA MyPyramid food groups. Only ten percent $(\mathrm{n}=$ 19) MAC softball players indicated they used the Food Guide Pyramid to make nutrition choices 'every day' or 'most days.' Almost half ( $\mathrm{n}=89$; $48 \%$ ) of the MAC softball players in the present study reported they used food labels 'every day' or 'most days' to make healthy choices.

The USDA Food Guide Pyramid recommends fruits and vegetables be consumed at least 5 to 9 times per day [9]. Many athletes in this study did not meet these recommendations. Of the 184 players who answered the question concerning their daily vegetable intake, more than half $(53 \% ; n=99)$ indicated they consumed less than 2 servings of vegetables per day; only $41 \%(n=75)$ reported consuming the minimum recommended 2 to 3 servings per day. Of the 185 MAC softball players who answered the question concerning their daily fruit intake, $45 \%(n=84)$ indicated they ate less than 2 servings a day; slightly more than half $(51 \% ; n=94)$ reported eating the recommended 2 to 3 servings per day. These results are similar to the findings of Batson, et al. who reported a majority of the 243 athletes surveyed consumed less than three servings of fruits and vegetables a day [6].

In general, research indicates athletes have a positive attitude toward the importance of eating a sport-enhancing diet. In the present study, the average score on the attitude toward a sport-enhancing diet was $1.9 \pm 0.4$ (range 1.0 - 3.7; possible range 1 - 24), meaning that MAC softball players tended to have a very positive attitude concerning nutrition. Seventy-nine percent of the MAC softball players either agreed or strongly agreed with the statement that a sport-enhancing diet will help them be a more successful softball player. In addition, almost every MAC softball player $(98 \% ; n=179)$ indicated it was important that coaches have a good attitude toward nutrition.

Werblow, et al. reported athletes had a generally favorable attitude toward nutrition [16]. Respondents also indicated it was important for coaches to have a favorable attitude toward nutrition [16]. In a different study, athletes reported attitude was a strong predictor $(\mathrm{r}=0.54)$ of adolescent students' intents to eat a healthful diet [25]. Schmalz reported that $95 \%$ of adolescent athletes believed a balanced diet was essential to an athlete [7]. Shifflett, et al. found that coaches, athletic trainers, and athletes believed it was important for athletes to adhere to a healthy diet [15].

Results indicated a significant relationship $(r=-0.17$; $\mathrm{p}=0.02$ ) between MAC softball players' nutrition knowledge and their attitude toward a sport-enhancing diet, with the better the player's attitude toward a sport-enhancing diet, the higher the player's nutrition knowledge. Werblow, et al. reports nutrition knowledge and attitude were positively correlated $(r=0.45 ; \mathrm{p}<$ 0.001) [16]. Their results indicated athletes who had received nutrition education in high school or college had significantly higher knowledge $(\mathrm{p}<0.001)$ and attitude ( $p<0.001)$ scores than those who had not [16]. Results of this study indicated a positive relationship between nutrition knowledge and attitudes, with higher knowledge and attitude scores associated with the athletes having had more nutrition education.

Several studies have examined athletes' preferred source of nutrition information. Overall, physicians were the preferred source for the Mid-American softball players who completed this study $(1.6 \pm 0.7)$, followed closely by athletic trainers (1.8 \pm 0.8$)$, a college nutrition or health course $(1.9 \pm 0.8)$, or a dietitian $(1.9 \pm 1.0)$. These results differ from studies conducted in the past when popular magazines, parents, and coaches appeared to be the preferred source of nutrition information. In 1984, Parr, Porter and Hodgson reported that athletes relied on their parents $(77 \%)$ for nutrition information and "other" sources (e.g., television, commercials, magazine advertisements, etc.) $66 \%$ of the time [26]. Barr reported that both regular college students and student athletes used books and magazines most frequently to obtain nutrition information, but that the "most useful" informa- 
tion came from print media and school courses [21]. Coaches were used as a source of information only $2 \%$ of the time by athletes [21].

Jacobson and Gemmel reported over $65 \%$ of the softball players they examined cited popular magazines as their most prominent information source for nutrition information, followed by friends, and athletic trainers [6]. The MAC softball players in the present study ranked athletic trainers highest on their source for nutrition information; they were much less likely to use their friends as a source for nutrition information.

Jacobson and Aldana surveyed 812 Division IA athletes from randomly selected universities [2]. In their study, $40 \%$ of the athletes indicated popular magazines as the most prominent source of nutrition information, followed by athletic trainers (31\%), friends (28\%), and college courses (25\%). In 2001, Jacobson, Sobonya and Ransone repeated their study by surveying 330 athletes from 16 randomly selected NCAA division IA universities [27]. The female athletes surveyed indicated most of their nutrition information came from university classes (18\%) and a nutritionist (16\%) [27]. Eleven percent of athletes indicated their primary source for nutrition information was their coach, while ten percent indicated they used popular magazines as their primary source of nutrition information [27]. Overall, the most cited sources for nutrition information were strength and conditioning coaches (22\%) followed by athletic trainers (19\%) [27]. It is interesting to note that the team physician was the primary source of nutrition information for only one percent of the athletes [27]. In contrast, in the present study, 91 percent of MAC softball players indicated they would be "very likely" or "likely" to use a physician as a resource for current information regarding nutrition.

Shifflett, et al. indicated the preferred sources for nutrition information were the athletes' parents (28\%) and their coaches (17\%) [15]. Zawila, et al. reported the top four nutrition information sources for female cross country runners were magazines, parents, coaches, and teammates [17]. In 2004, a study found that athletic trainers were the primary source of nutrition information for athletes from a diversified sample of NCAA Division I athletes [8]. In general, athletes have tended to rely on non-trained professionals for nutrition advice. College athletes should be encouraged to seek out dietitians trained in sports nutrition for accurate advice.

Athletes vary in the amount of formal nutrition training they receive prior to and while in college. Although our study did not examine the amount of nutrition MAC softball players were exposed to prior to entering college, we did ask athletes to identify whether or not they had taken any college-level nutrition course or any other course that contained a unit in nutrition while in college. Eight-four (46\%) athletes reported they had not taken any college-level nutrition course nor had they received any nutrition education in any other college course.

Werblow, et al. indicated $41 \%$ of the division I college athletes surveyed had never been exposed to a high school or college nutrition course or a course in which nutrition was integrated and only 8 percent had taken a college nutrition course [16]. Jacobson, et al. reported athletes were more likely to have received nutrition information 'always' or 'often' (55\%) rather than 'seldom' or 'never' (45\%) [27]. Of the 243 division I athletes surveyed by Batson, et al., less than $40 \%$ reported receiving nutritional information before college [22].

Research findings suggest athletes want to learn more about nutrition and athletic performance. In the present study, most MAC softball players (95\%) believed it would be helpful for athletes to have a course in nutrition. Similarly, $97 \%$ of division I college football players surveyed by Jonnalagadda, et al. reported they were interested in learning more about nutrition and enhancing performance [23].

Zawila, et al. found no relationship ( $r=0.19 ; \mathrm{p}=0.15)$ between the number of nutrition sources used by cross-country runners and their nutrition knowledge score [17]. Although the present study did not compare the total number of sources players used to obtain nutrition information, players' preferred sources were compared to those who passed or failed the nutrition knowledge questions. The only significant finding related to players who indicated athletic trainers were their preferred source of nutrition information. Among these athletes, only one-third received a score of 60 percent or higher on the nutrition knowledge questions.

A thorough search of the literature found little information concerning an athlete's nutrition knowledge when compared to both an athlete's nutritional choices and nutritional practices. The same was true when an athlete's attitude toward a sport-enhancing diet was compared to their nutritional choices and nutritional practices. More research needs to be completed to further understand how an athlete's nutrition knowledge and attitude affects their food choices and practices.

\section{Practical Application}

Over the past few decades, research has consistently shown that athletes make poor nutrition choices, practice questionable eating habits, and have a below average understanding of their nutritional needs. This study affirms these observations, raising the question why athletes have not become more knowledgeable about nutri- 
tion or changed their nutritional practices over the past twenty years. At the collegiate level, a great deal of emphasis is placed on athletic performance, yet most athletic departments do not have (or do not allocate) adequate funds to hire a nutrition consultant for their athletic teams. In the present study, only one of five athletes (21.6\%) had ever consulted with a dietitian. Most athletic departments worry more about having enough money in their budgets to feed their players on the road rather than worrying about the quality of the meals purchased. Perhaps the larger question is whether or not nutrition is perceived as an important part of an athlete's total training experience, like practice or strength training are perceived. Coaches, athletic trainers, strength and conditioning coaches, and athletic departments should all be encouraged to do a better job of making sports nutrition, and overall personal nutrition, an integral part of every player's collegiate athletic experience.

\section{Acknowledgement}

This article would not have been possible without the participation of the Mid American Conference softball players who completed the questionnaire. The authors would also like to thank Dr. Jim Jones, Asst Director Research \& Design, Ball State University, for his assistance with the statistical analysis.

\section{REFERENCES}

[1] W. D. McArdle, F. I. Katch and V. L. Katch, "Sports \& Exercise Nutrition,” Lippincott Williams \& Wilkins, Philadelphia, 1999.

[2] B. H. Jacobson and S. G. Aldana, "Current Nutrition Practice and Knowledge of Varsity Athletes," Journal of Applied Sciences Research, Vol. 6, No. 4, 1992, pp. 232-238.

[3] B. Kiens, J. L. Ivy and L. M. Burke, "Carbohydrates and Fat for Training and Recovery," Journal of Sports Sciences, Vol. 22, No. 1, 2004, pp. 15-20.

[4] W. S. Holt, "Nutrition and Athletes," American Family Physician, Vol. 47, No. 8, 1993, pp. 1757-1764.

[5] C. A. Rosenbloom and R. Skinner, "College Athletes. In: Sports Nutrition: A Practice Manual for Professionals," Dunford, M 4th edition, IL: The American Dietetic Association, Chicago, 2006.

[6] B. H. Jacobson and H. A. Gemmell, "Nutrition Information Sources of College Varsity Athletes,” Journal of Applied Sport Science Research, Vol. 5, No. 4, 1991, pp. 204-207.

[7] K. Schmalz, "Nutritional Beliefs and Practices of Adolescent Athletes,” Journal of School Nursing, Vol. 9, No. 2, 1993, pp. 18-22.

[8] R. D. Burns, M. R. Schiller, M. A. Merrick and K. N. Wolf, "Intercollegiate Student Athlete Use of Nutritional
Supplements and the Role of Athletic Trainers and Dietitians in Nutrition Counseling," Journal of the American Dietetic Association, Vol. 104, No. 2, 2004, pp. 246-249. doi:10.1016/j.jada.2003.11.013

[9] Department of Labor (DOL). "Title IX, Education Amendments of 1972,” Available at: http://www.dol.gov/oasam/regs/statutes/titleix.htm Accessed November 18, 2007.

[10] R. V. Acosta and L. J. Carpenter, "Women in Intercollegiate Sport: A Longitudinal, National Study Thirty One Year Update,” 1977-2008, 2008. Available at http://www.acostacarpenter.org/ Accessed February 14, 2009.

[11] NCAA. 1981-82-2006-07, “NCAA® Sports Sponsorship and Participation Rates Report,” 2008. Available at: http://www.ncaapublications.com/Uploads/PDF/Pariticip at-Rates20084232c5b7-6441-412c-80f1-7d85f3536a51.p df

Accessed February 17, 2009.

[12] Ajzen, I. "Constructing a TpB Questionnaire: Conceptual and Methodological Considerations,” 2006. Available at: http://people.umass.edu/aizen/pdf/tpb.measurement.pdf Accessed February 17, 2009.

[13] A. Bayless, "Effect of Diet, Physical Activity, and Lifestyle Characteristics on Body Weight of Incoming Freshmen at a Midwestern University,” Masters Thesis. Ball State University, Muncie, 2006.

[14] Department of Health and Human Services (DHHS) and U. S. Department of Agriculture (USDA), "Dietary Guidelines for Americans 2005,” 6th Edition, Washington, DC: U. S. Government Printing Office, 2005.

[15] B. Shifflett, C. Timm and L. Kahanov, "Understanding of Athletes' Nutritional Needs among Athletes, Coaches, and Athletic Trainers," Research Quarterly for Exercise and Sport, Vol. 73, No. 3, 2002, pp. 357-362.

[16] J. A. Werblow, H. M. Fox and A. Henneman, "Nutritional Knowledge, Attitudes, and Food Patterns of Women Athletes," Journal of the American Dietetic Association, Vol. 73, 1978, pp. 242-245.

[17] L. G. Zawila, C. M. Steib and B. Hoogenboom, “The Female Collegiate Cross-country Runner: Nutritional Knowledge and Attitudes," Journal of Athletic Training, Vol. 38, No. 1, 2003, pp. 67-74.

[18] SPSS Inc. SPSS (12.0) for Windows. Chicago, 2005.

[19] D. A. Abood, D. R. Black and R. D. Birnbaum, "Nutrition Education Intervention for College Female Athletes," Journal of Nutrition Education and Behavior, Vol. 36, No. 3, 2004, pp. 135-139. doi:10.1016/S1499-4046(06)60150-4

[20] P. D. Douglas and J. G. Douglas, "Nutrition Knowledge and Food Practices of High School Athletes," Journal of the American Dietetic Association, Vol. 84, No. 10, 1984, pp. 1198-1202.

[21] S. I. Barr, "Nutrition Knowledge of Female Varsity Athletes and University Students,” Journal of the American 
Dietetic Association, Vol. 87, No. 12, 1987, pp. 16601664.

[22] J. P. Batson, T. Sease, M. Stanek and M. J. Leski, "Sports Nutrition in Collegiate Athletes," Medicine \& Science in Sports \& Exercise, Vol. 36, No. 5, Supplement, S348, 2004.

[23] S. S. Jonnalagadda, C. A. Rosenbloom and R. Skinner, "Dietary Practices, Attitudes, and Physiological Status of Collegiate Freshman Football Players," Journal of Strength \& Conditioning Research, Vol. 15, No. 4, 2001, pp. 507-513.

[24] M. L. McCullough and W. C. Willett, "Evaluating Adherence to Recommended Diets in Adults: The Alternate Healthy Eating Index,” Public Health Nutrition, Vol. 9,
No. 1A, 2006, pp. 152-157.

[25] D. R. Backman, E. H. Haddad, J. W. Lee, P. K. Johnston and G. E. Hodgkin, "Psychosocial Predictors of Healthful Dietary Behavior in Adolescents," Journal of Nutrition Education and Behavior, Vol. 34, No. 4, 2002, pp. 184-193. doi:10.1016/S1499-4046(06)60092-4

[26] R. B. Parr, M. A. Porter and S. C. Hodgson, "Nutrition Knowledge and Practice of Coaches, Trainers, and Athletes,” Physical Sportsmed, Vol. 12, No. 3, 1984, pp. 127-138.

[27] B. H. Jacobson, C. Sobonya and J. Ransone, "Nutrition Practices and Knowledge of College Varsity Athletes: A Follow-up," Journal of Strength \& Conditioning Research, Vol. 15, No. 1, 2001, pp. 63-68. 